Article

\title{
Nano-Structural Investigation on Cellulose Highly Dissolved in Ionic Liquid: A Small Angle X-ray Scattering Study
}

\author{
Takatsugu Endo ${ }^{1, *}$, Shota Hosomi ${ }^{1}$, Shunsuke Fujii ${ }^{1}$, Kazuaki Ninomiya ${ }^{2}$ and \\ Kenji Takahashi ${ }^{1, *}$ \\ 1 Faculty of Natural System, Institute of Science and Engineering, Kanazawa University, Kakuma-machi, \\ Kanazawa 920-1192, Japan; hsmst14@gmail.com (S.H.); fujii-sh091@stu.kanazawa-u.ac.jp (S.F.) \\ 2 Institute for Frontier Science Initiative, Kanazawa University, Kakuma-machi, Kanazawa 920-1192, Japan; \\ ninomiya@se.kanazawa-u.ac.jp \\ * Correspondence: tkendo@staff.kanazawa-u.ac.jp (T.E.); ktkenji@staff.kanazawa-u.ac.jp (K.T.); \\ Tel.: +81-76-234-4807 (T.E.); +81-76-234-4828 (K.T.)
}

Academic Editor: Hua Zhao

Received: 21 December 2016; Accepted: 18 January 2017; Published: 21 January 2017

\begin{abstract}
We investigated nano-structural changes of cellulose dissolved in 1-ethyl-3methylimidazolium acetate —an ionic liquid (IL)—using a small angle X-ray scattering (SAXS) technique over the entire concentration range (0-100 mol \%). Fibril structures of cellulose disappeared at $40 \mathrm{~mol} \%$ of cellulose, which is a significantly higher concentration than the maximum concentration of dissolution (24-28 mol \%) previously determined in this IL. This behavior is explained by the presence of the anion bridging, whereby an anion prefers to interact with multiple $\mathrm{OH}$ groups of different cellulose molecules at high concentrations, discovered in our recent work. Furthermore, we observed the emergence of two aggregated nano-structures in the concentration range of 30-80 mol $\%$. The diameter of one structure was $12-20 \mathrm{~nm}$, dependent on concentration, which is ascribed to cellulose chain entanglement. In contrast, the other with $4.1 \mathrm{~nm}$ diameter exhibited concentration independence and is reminiscent of a cellulose microfibril, reflecting the occurrence of nanofibrillation. These results contribute to an understanding of the dissolution mechanism of cellulose in ILs. Finally, we unexpectedly proposed a novel cellulose/IL composite: the cellulose/IL mixtures of 30-50 mol \% that possess liquid crystallinity are sufficiently hard to be moldable.
\end{abstract}

Keywords: ionic liquids; cellulose; small angle X-ray scattering; dissolution; composites

\section{Introduction}

Cellulose - the major component of wood-is renewable, and is the most abundant biopolymer on Earth; therefore, its advanced unitization is crucial for a sustainable society. However, the severe limiting factor is that cellulose does not dissolve in any conventional solvents. A new class of cellulose solvents-ionic liquids (ILs)—was discovered in 2002 [1]. ILs are defined as salts that are liquid around room temperature, and some of them are able to efficiently dissolve cellulose [2,3]. ILs have some outstanding properties as cellulose solvents compared with those used previously: high designability (any appropriate physicochemical properties can be introduced by modifying the cation/anion structures or altering their combination), single component, practically nonvolatile and nonflammable, and highly thermally/chemically/electrochemically stable. Since these green solvents can be a breakthrough for cellulose science, understanding how cellulose dissolves in ILs is a very important issue. Many studies have been conducted thus far to contribute to this aim [2-5]. The most crucial finding is that IL anions play a major role in the dissolution by disrupting the 
inter- and intramolecular hydrogen-bonding network of cellulose. These anions mainly interact with the hydrogen of the $\mathrm{OH}$ groups in a 1:1 ratio [6], although it was suggested by molecular dynamics (MD) simulations that some anions participate in multiple interactions with the OH groups $[7,8]$. The role of the cations seems to be less significant; nevertheless, they unquestionably have some impact on the dissolution. Although the definitive role is still controversial, MD simulations have indicated the presence of weak hydrophobic interactions between the cations and the glucose ring of cellulose [4,5], which explains why aromatic cations tend to exhibit high dissolution ability [2,3].

It is well known that the concentration of a solution governs the state of dissolution of solute molecules. Particularly at high concentrations, self-assembly phenomena (e.g., lyotropic liquid crystal or micelle formation) are observed. However, a concentration regime of more than 30 mol $\%$ (mol \% here is defined as glucose unit/(glucose unit + IL)) - which is considered to exceed the maximum solubility because the ratio of IL to the $\mathrm{OH}$ groups of cellulose is greater than 1:1-has been completely overlooked. Recently, we performed a structural investigation on cellulose dissolved in 1-ethyl-3-methylimidazolium acetate ([Emim][OAc])—as the most representative IL for cellulose dissolution-over the entire concentration range (0-100 mol \%) by means of wide-angle X-ray scattering with the aid of quantum chemical calculations and ${ }^{13} \mathrm{C}$ solid-state NMR spectroscopy [9]. We demonstrated that the states at concentrations $\geq 30 \mathrm{~mol} \%$ showed anomalous deconstruction and restructuring of cellulose, as schematically summarized in Figure 1 . Even at 40 mol \%, the original crystalline structure of cellulose is absent. Furthermore, a new cellulose/IL complex with high structural periodicity emerges at approximately $35 \mathrm{~mol} \%$. It was revealed that these characteristic features originated from the anion bridging phenomenon, which is when one anion interacts with multiple $\mathrm{OH}$ groups of different cellulose chains. At concentrations $\leq 25 \mathrm{~mol} \%$, the anion/OH group interaction is mainly 1:1 (non-bridging), as previously reported [6-8]. In contrast, the anion bridging state is energetically preferred at the higher concentrations, which induces intriguing structural changes in cellulose.

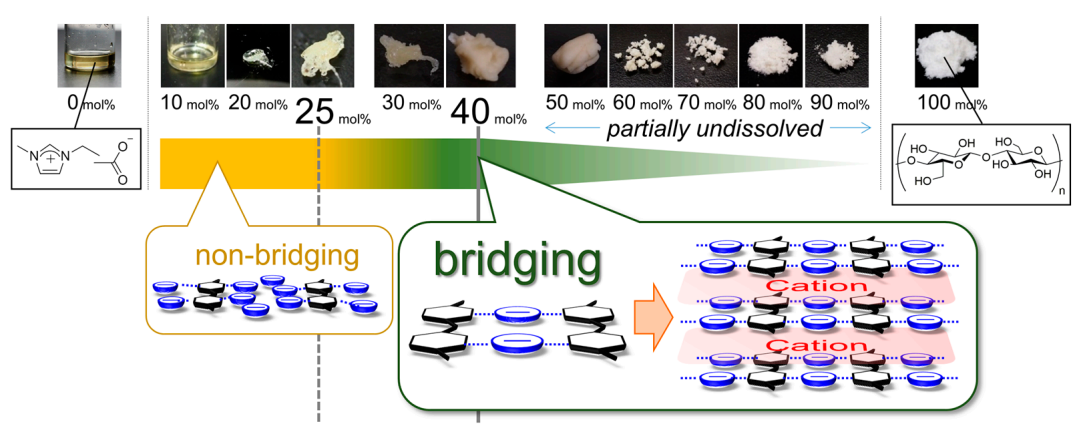

Figure 1. Schematic summary of Reference [9]. Below $25 \mathrm{~mol} \%$, the anions mainly interact with the $\mathrm{OH}$ groups of cellulose in a 1:1 ratio (non-bridging), while some portion of the anions have multiple interactions with the $\mathrm{OH}$ groups $[7,8]$. In the concentration range of $25-40 \mathrm{~mol} \%$, the interaction state of the anion-OH group gradually switches from non-bridging to bridging, which induces the emergence of the cellulose/[Emim][OAc] (1-ethyl-3-methylimidazolium acetate) complex structure. The anions bridge cellulose chains, forming a sheet structure. The sheets are stacked upon each other, intercalated by the cations, forming a layered structure. Note that the exact structure is less ordered than the schematic; i.e., the cellulose chains and the cellulose/anion sheets are not completely straight and flat, respectively. The transformation to the bridging state is completed at $40 \mathrm{~mol} \%$, which enables the IL to thoroughly deconstruct the cellulose crystalline structure at this high concentration. The bridging state is maintained above $40 \mathrm{~mol} \%$, where undissolved cellulose co-exists. Note that in the concentration range of $10-70 \mathrm{~mol} \%$, the mixtures exhibit a lyotropic cholesteric liquid crystallinity, associated with the chain alignment.

Although these findings provided a new aspect of cellulose dissolution state in IL, knowledge is limited at the molecular level. It is well known that cellulose exhibits a hierarchical structure [10-12]: 
at the nano-level, it forms microfibrils with the diameter of several $\mathrm{nm}$, which gather together to form larger bundles. From this standpoint, this study is devoted to investigating the structural changes in cellulose/[Emim][OAc] at the nano-level-particularly focusing on the high concentration regime-by means of small angle X-ray scattering (SAXS) measurements, supported by scanning electron microscopy.

\section{Results and Discussion}

Figure 2 shows SAXS patterns of cellulose/[Emim][OAc] in the Kratky plot (Intensity $\times q^{2}$ versus $q$ ) at $0-100 \mathrm{~mol} \%$ concentration. In this plot, scattering from nanostructures appears as a peak [13]. For pure cellulose (100 mol \%), only a shoulder is observable in the plot, indicating the presence of structures larger than the detectable limit of the current SAXS setup $(>50 \mathrm{~nm})$. The shoulder scattering would come from bundles of cellulose microfibrils, the presence of which was confirmed by SEM observation (far-right in Figure 3). This shoulder is not observed for the cellulose/[Emim][OAc] mixtures up to a concentration of $40 \mathrm{~mol} \%$, even though the upper limit of dissolution at room temperature for this system was reported to be $26-28 \mathrm{~mol} \%[14,15]$. This behavior is consistent with the findings obtained at the molecular level [9], and can be explained by the concept of anion bridging. Namely, the anion bridging form-which is energetically preferred around a concentration of $40 \mathrm{~mol}$ $\%$ (and above) — can completely deconstruct the crystalline structure of cellulose, and consequently, the fiber structures at this concentration. These SAXS results do not contradict the SEM observations shown in Figure 3, while SEM only detects surface morphology. The bundled fibers were observed at $70-100 \mathrm{~mol} \%$. At $60 \mathrm{~mol} \%$, surface roughness rather than fiber structures was seen. The surface became smoother with decreasing cellulose concentration, and eventually no clear structure was detected at $30 \mathrm{~mol} \%$.

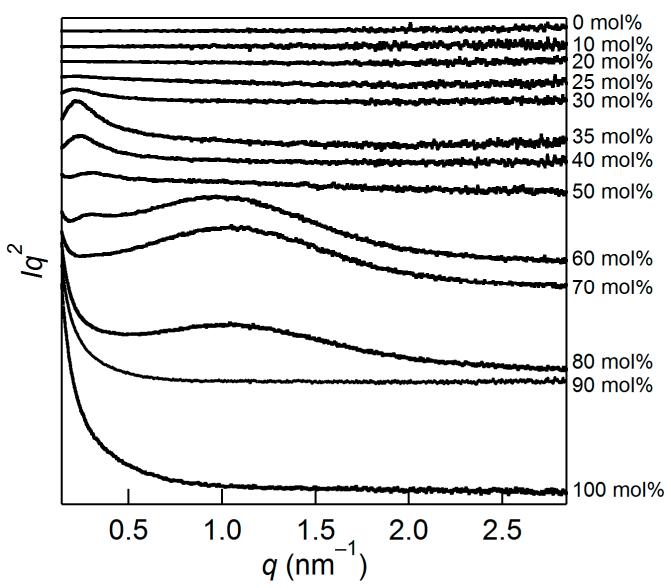

Figure 2. Small angle X-ray scattering (SAXS) patterns of the cellulose/[Emim][OAc] mixtures in the Kratky plot.

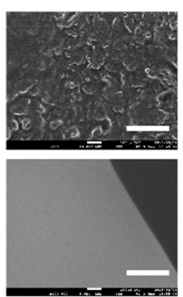

$30 \mathrm{~mol} \%$

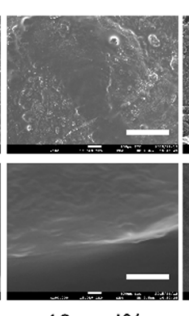

$40 \mathrm{~mol} \%$

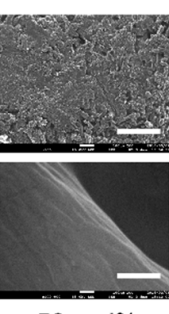

$50 \mathrm{~mol} \%$

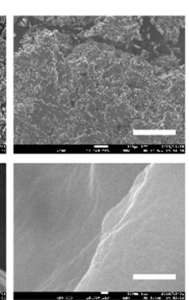

$60 \mathrm{~mol} \%$

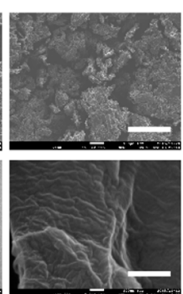

$70 \mathrm{~mol} \%$

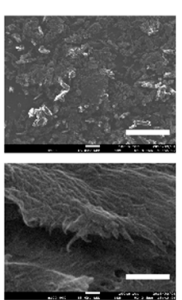

$80 \mathrm{~mol} \%$

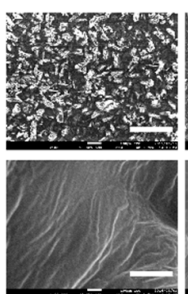

$90 \mathrm{~mol} \%$

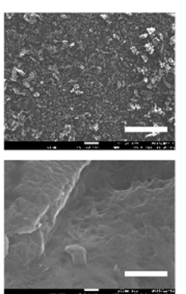

$100 \mathrm{~mol} \%$

Figure 3. SEM micrographs. White scale bars for the top $(100 \times)$ and bottom $(100,000 \times)$ figures represent $300 \mu \mathrm{m}$ and $300 \mathrm{~nm}$, respectively. 
There is another characteristic feature in Figure 1, which is the emergence of two new peaks in the concentration range of 30-80 $\mathrm{mol} \%$. This clearly indicates the presence of two nanostructures (or aggregations) which are not present in either intact cellulose or [Emim][OAc]. To derive their size and conduct a detailed discussion, the peaks at 1.1 and $0.3 \mathrm{~nm}^{-1}$ were fitted with the generalized Guinier-Porod function [16]. The generalized Guinier-Porod function experimentally combines the Guinier and Porod regions, and is expressed as:

$$
\begin{gathered}
I(q)=\frac{I(0)}{q^{s}} \exp \left(\frac{-q^{2} R_{g}^{2}}{3-s}\right) \text { for } q \leq q_{1}, \\
I(q)=\frac{D}{q^{d}} \text { for } q \geq q_{1},
\end{gathered}
$$

where

$$
\begin{gathered}
q_{1}=\frac{1}{R_{g}}\left[\frac{(d-s)(3-s)}{2}\right]^{\frac{1}{2}}, \\
D=I(0) \exp \left(\frac{-q_{1}^{2} R_{g}^{2}}{3-s}\right) q_{1}^{(d-s)} \\
=\frac{I(0)}{R_{g}^{(d-s)}} \exp \left[-\frac{(d-s)}{2} \frac{(d-s)(3-s)}{2}\right]^{\frac{d-s}{2}},
\end{gathered}
$$

and where $I(0)$ is the scattered intensity at $q=0$ and $R_{\mathrm{g}}$ is the radius of gyration. A value of $s=0$ occurs when the scatterer is a three-dimensional globular object (such as a sphere). For one- (rod) and two-dimensional (lamellae or platelet) objects, the values are defined as 1 and 2, respectively.

The fitted results are displayed in Figure 4a. Note that the Porod function was employed for the shoulder scatterer; therefore, the sum of two generalized Guinier-Porod functions and one Porod function was utilized to reproduce the overall patterns. All experimental patterns at the concentrations of $30-80 \mathrm{~mol} \%$ were well reproduced in the entire $q$ range by the combination of the functions. The derived parameters are summarized in Table 1 . The $s$ values for the aggregates were mostly zero, strongly implying that the shape of these structures was close to a sphere. The diameter of a sphere $(R)$ can be determined from $R_{\mathrm{g}}$ as

$$
R^{2}=\frac{5}{3} R_{g}^{2}
$$

The concentration dependence of the $R$ values is shown in Figure $4 \mathrm{~b}$. The behavior of the two structures with varying concentration is quite different. The structure with smaller $R$ exists only at $50-80 \mathrm{~mol} \%$, and its size is independent of the concentration. In contrast, the structure with larger $R$ is observed at 30-80 mol \%, exhibiting concentration dependency. The invariant $4.1 \mathrm{~nm}$ diameter for the smaller scatterer is reminiscent of the microfibril of cellulose, whose size was reported as $4-5 \mathrm{~nm}$ for Avicel $[17,18]$. It is well known that cellulose fibrillation occurs with mechanical treatment in the presence of solvents [19]. The association of the 4.1-nm-diameter scatterer with the cellulose microfibril is in line with the fact that the shoulder scatterer associated with large bundles also does not exist at concentrations below $50 \mathrm{~mol} \%$. If so, then the result demonstrates that the interfibril breakages occur more easily than the intrafibril ones. The dynamic dissolution process can proceed similarly. 

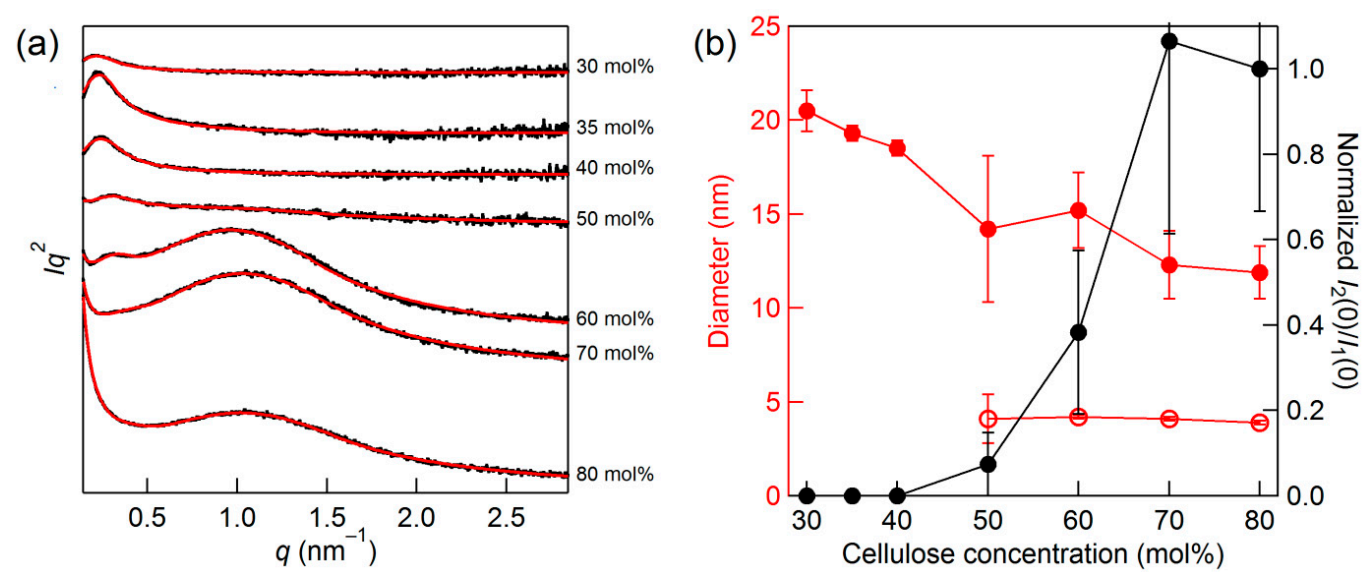

Figure 4. (a) SAXS patterns of the cellulose/[Emim][OAc] mixtures in the Kratky plot for the concentrations of 30-80 mol \%. Black curves are the observed patterns, while the red curves are the theoretical patterns comprising the sum of two generalized Guinier-Porod functions and one Porod function; (b) Red: Diameter changes of the aggregated structures, assuming a sphere. Filled and open symbols are for large and small aggregates, respectively. Black: The normalized $I_{2}(0) / I_{1}(0)$ change, where $I_{1}(0)$ and $I_{2}(0)$ are the scattered intensities of the aggregates at $q=0$. The subscripts 1 and 2 are for the large and small aggregates, respectively. The \pm signs represent standard deviation produced in the fitting procedures based on a nonlinear regression method.

Table 1. SAXS parameters obtained from Figure $4 \mathrm{a}$. The subscripts 1,2 , and $s$ are for the large aggregates, small aggregates, and shoulder scattering, respectively. The \pm signs represent standard deviation produced in the fitting procedures based on a nonlinear regression method.

\begin{tabular}{cccccccc}
\hline $\begin{array}{c}\text { Cellulose } \\
\text { Concentration/mol \% }\end{array}$ & $\boldsymbol{R}_{\mathbf{g} \mathbf{1}} \mathbf{n} \mathbf{m}$ & $\boldsymbol{d}_{\mathbf{1}}$ & $\boldsymbol{s}_{\mathbf{1}}$ & $\boldsymbol{R}_{\mathbf{g} \mathbf{2}} \mathbf{n} \mathbf{n}$ & $\boldsymbol{d}_{\mathbf{2}}$ & $\boldsymbol{s}_{\mathbf{2}}$ & $\boldsymbol{d}_{\mathbf{s}}$ \\
\hline 30 & $7.9 \pm 0.4$ & $4.0 \pm 0.0$ & $0.0 \pm 0.1$ & $\mathrm{n} / \mathrm{a}$ & $\mathrm{n} / \mathrm{a}$ & $\mathrm{n} / \mathrm{a}$ & $\mathrm{n} / \mathrm{a}$ \\
35 & $7.5 \pm 0.2$ & $3.8 \pm 0.0$ & $0.0 \pm 0.1$ & $\mathrm{n} / \mathrm{a}$ & $\mathrm{n} / \mathrm{a}$ & $\mathrm{n} / \mathrm{a}$ & $\mathrm{n} / \mathrm{a}$ \\
40 & $7.1 \pm 0.1$ & $3.9 \pm 0.0$ & $0.0 \pm 0.1$ & $\mathrm{n} / \mathrm{a}$ & $\mathrm{n} / \mathrm{a}$ & $\mathrm{n} / \mathrm{a}$ & $\mathrm{n} / \mathrm{a}$ \\
50 & $5.5 \pm 1.5$ & $3.0 \pm 0.3$ & $0.0 \pm 0.8$ & $1.6 \pm 0.5$ & $3.5 \pm 0.4$ & $0.0 \pm 0.9$ & $4.0 \pm 1.5$ \\
60 & $5.9 \pm 0.5$ & $4.0 \pm 0.0$ & $0.0 \pm 0.0$ & $1.6 \pm 0.0$ & $4.0 \pm 0.0$ & $0.1 \pm 0.1$ & $4.0 \pm 0.0$ \\
70 & $4.9 \pm 0.2$ & $3.6 \pm 0.8$ & $0.1 \pm 0.1$ & $1.6 \pm 0.0$ & $4.0 \pm 0.0$ & $0.1 \pm 0.1$ & $4.0 \pm 0.0$ \\
80 & $4.7 \pm 0.0$ & $3.8 \pm 0.4$ & $0.1 \pm 0.1$ & $1.5 \pm 0.1$ & $4.0 \pm 0.0$ & $0.1 \pm 0.1$ & $4.0 \pm 0.0$ \\
\hline
\end{tabular}

The next question is on the origin of the larger scatterer. During the dissolution process, MD simulations observe the peeling of cellulose chains on the fibril surface from the chain edges by intercalation of IL ions [20,21]. Since the intramolecular hydrogen bonding of peeled chains is considerably disrupted by the IL ions, chain bending and twisting occur [22,23]. This flexibility of the terminal parts may enable such chains to entangle, which could correspond to the larger aggregate. This structure disappears at $25 \mathrm{~mol} \%$, because all $\mathrm{OH}$ groups can interact with an anion in a 1:1 ratio (non-bridging) at this concentration, which unravels the entanglement. Another piece of indirect evidence for the assignment of this structure is the moldability of the cellulose/IL mixture. After several hours of mixing cellulose/[Emim][OAc], the samples of 30-50 mol \% intriguingly became mechanically sufficiently hard to be molded (Figure 5), and this moldability disappeared at concentrations below $30 \mathrm{~mol} \%$. The idea that cellulose entanglement is the origin of mechanical strength is well-established for cellulose hydrogels [24,25]. Although exploring the potential of this cellulose/IL composite film is beyond the scope of this paper, it is worth noting that among reported cellulose/IL composite materials [26-29], the emergence of the moldability in cellulose/IL system with liquid crystallinity [9] (in a 10-70 mol \% regime) has been discovered here for the first time. The aggregate size decreases with increasing cellulose concentration (Figure $4 \mathrm{~b}$ ), probably because of the decrease in the numbers of glucose units in the chains and the IL ions that participate in the aggregates. 


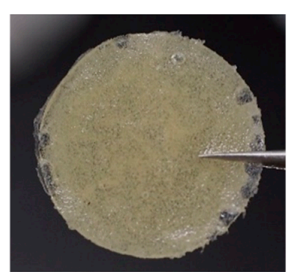

$30 \mathrm{~mol} \%$

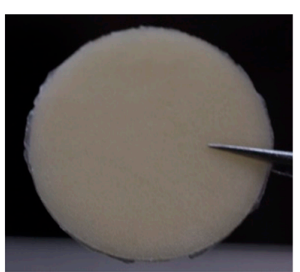

$40 \mathrm{~mol} \%$

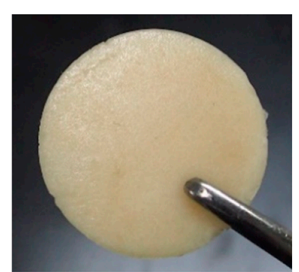

$50 \mathrm{~mol} \%$

Figure 5. Cellulose/IL (ionic liquid) composite films (30-50 mol \%) with a diameter of $25 \mathrm{~mm}$ and thickness of $1 \mathrm{~mm}$. The opacity of the film of $40 \mathrm{~mol} \%$ is attributed to micro air bubbles [9] and surface (or interfacial) roughness, which were confirmed in the $30 \mathrm{~mol} \%$ film and the SEM images (Figure 3 top). Conversely, the presence of undissolved crystals is also a reason for the opacity at $50 \mathrm{~mol} \%$.

The mixture with $25 \mathrm{~mol} \%$ cellulose-which gives some scattering but no peak in the Kratky plot-cannot be fitted with the generalized Guinier-Porod model, and thus would need another theoretical model. Rein et al. [15] reported the SAXS profile of the transparent gel-like mixture of cellulose/[Emim][OAc] at $28 \mathrm{~mol} \%$, which was prepared by rapid evaporation of a volatile co-solvent. They applied a combination of the Debye-Bueche [30] and Ornstein-Zernike [31] equations for the pattern to gain correlation lengths of the scatterer. The former and latter equations express the scattering from a long-range inhomogeneity and a fluctuation in polymer chains, and were employed to describe the major and minor components in the pattern, respectively. The Debye-Bueche equation is

$$
I(q)=\frac{A}{\left(1+\xi^{2} q^{2}\right)^{2}}
$$

where $\xi$ is the correlation length. The Ornstein-Zernike equation is

$$
I(q)=\frac{A}{1+\xi^{2} q^{2}}
$$

The quality of our data for $25 \mathrm{~mol} \%$ does not require the Ornstein-Zernike equation, and yields a correlation length of $4.8 \mathrm{~nm}$ with the Debye-Bueche equation (Figure 6). This value is smaller than the reported value of $18 \mathrm{~nm}$ [15], possibly owing to the slightly lower cellulose concentration of our sample and the differences in the sample preparation procedures, whereas the differences in the fitting range of the SAXS pattern and data quality (lower $\mathrm{S} / \mathrm{N}$ ratio for our results) could contribute to the gap of the correlation length. In any case, it is indicated that the $25 \mathrm{~mol} \%$ sample does not form definite structures, which were seen in the samples with higher cellulose concentrations.

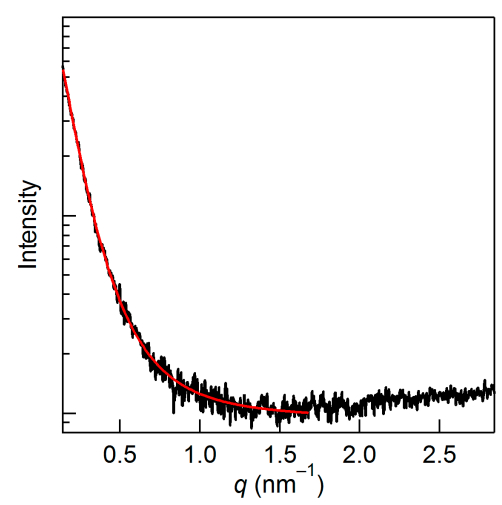

Figure 6. A single logarithmic SAXS pattern of the mixture at $25 \mathrm{~mol} \%$. The Debye-Bueche equation was applied (red line) to reproduce the experimental pattern. 


\section{Materials and Methods}

Microcrystalline cellulose (Avicel PH-101, Sigma-Aldrich, St. Louis, MO, USA) and [Emim][OAc] (>95\%, IoLiTec, Heilbronn, Germany) were dried by heating under vacuum (1 Pa) before use. Avicel PH-101 contains approximately $5 \mathrm{wt} \%$ of water, and after drying at $343 \mathrm{~K}$ for $3 \mathrm{~h}$, the level of water detectable by a moisture analyzer (Sartorius, model MA35) was zero. The water content in the IL was measured using ${ }^{1} \mathrm{H}-\mathrm{NMR}$ (JEOL JNM-ECS400 or JNM-ECA600, Tokyo, Japan), and no water peak signal was detected after one day of drying at $323 \mathrm{~K}$. The typical sample-mixing procedure was as follows: $0.1 \mathrm{~g}$ of Avicel was added to a certain amount of the IL in a vial and mixed with a spatula until the mixture appeared visually homogenous (normally after $5 \mathrm{~min}$ ). The mixtures were prepared in the range of 10-90 mol \% at every 5 or $10 \mathrm{~mol} \%$. After one day (which is considered a sufficient period to reach an experimental equilibrium state [9]), the mixture was packed within a Teflon cell with $1 \mathrm{~mm}$ thickness. The cell was sandwiched between two sheets of Kapton film ( $5 \mu \mathrm{m}$ thickness) and sealed with grease (Apiezon N). These procedures were performed in an inert-atmosphere glove box (the water content was less than $10 \mathrm{ppm}$ ). In the mixtures prepared with the current condition, no detectable chemical reactions or cellulose degradation occurred [9].

SAXS measurements were conducted with a NANO-Viewer (IP system, Rigaku Co., Ltd, Tokyo, Japan) with a $\mathrm{Cu} \mathrm{K} \alpha$ radiation source $(\lambda=0.154 \mathrm{~nm})$ at an applied voltage of $40 \mathrm{kV}$ and a filament current of $30 \mathrm{~mA}$. The distance between the sample and the detector was set at $700 \mathrm{~mm}$ $\left(q=0.142-2.844 \mathrm{~nm}^{-1}\right)$. The samples were irradiated for $1 \mathrm{~h}$. The obtained two-dimensional image was transformed into a one-dimensional pattern for theoretical analyses. It should be noted that anisotropic images were not observed in any of our data because the cellulose sample used here was powder. The scattering experiments were conducted three times with a cellulose concentration of more than 40 mol $\%$ at different spots in the same sample, and the averaged patterns were used for analyses. This is because there exists inhomogeneity in the sample with such high concentrations due to the presence of undissolved (intact cellulose) regions [9]. Backgrounds including scattering from Kapton films were subtracted from the scattering patterns.

A field emission scanning electron microscope (FE-SEM, JEOL JSM-7100F) was operated at $15 \mathrm{kV}$. The samples were coated with $\mathrm{Au} / \mathrm{Pt}$ using an ion sputter coater for SEM observation.

\section{Conclusions}

We have investigated structural changes of cellulose/[Emim][OAc] at the nano-level over the entire concentration range of $0-100 \mathrm{~mol} \%$ by SAXS measurements with the aid of SEM observations. The shoulder scattering in the Kratky plot ascribed to bundles of cellulose microfibrils does not exist up to $40 \mathrm{~mol} \%$. This finding is well explained by the fact that at high concentrations, the anions are energetically preferred to have multiple interactions with $\mathrm{OH}$ groups of cellulose chains (anion bridging), which enables the deconstruction of the cellulose crystallinity, and consequently fibril structures at $40 \mathrm{~mol} \%$. We observed two aggregated structures that are not observed either in intact cellulose or in the IL at 30-80 mol \%. The smaller structure-which is reminiscent of a microfibril with an average diameter of $4.1 \mathrm{~nm}$-does not show concentration dependency. Conversely, the larger one depends on the concentration, and its size is in the range of $12-20 \mathrm{~nm}$. The structure originates from cellulose chain entanglement, which is the origin of the moldability of the cellulose/IL composite films that possess liquid crystallinity.

Since the local concentration of cellulose in ILs at the early stage of the dissolution process should be much higher than that of the consequent solution, the nano-structures observed in the high concentrations can be intermediate states for the dissolution process. Therefore, our findings contribute to an understanding of the dissolution mechanism of cellulose in the IL; inter-fibrillation occurs more easily than intra-fibrillation, and cellulose chains are entangled with each other after IL ions peel the chains from fibrils, which may be one reason for the slow dissolution process of cellulose in ILs. 
Acknowledgments: This study was supported in part by Advanced Low Carbon Technology Research and Development Program (ALCA) (Grant number 2100040), Cross-ministerial Strategic Innovation Promotion Program (SIP), and Center of Innovation Program "Construction of next-generation infrastructure using innovative materials: Realization of safe and secure society that can coexist with the Earth for centuries" from Japan Science and Technology Agency, and also by JSPS KAKENHI Grant Number 15H04193.

Author Contributions: T.E. and K.T. conceived and designed the experiments; S.H. and S.F. performed the experiments; T.E. analyzed the data; T.E. wrote the paper in consultation with K.T. and K.N.

Conflicts of Interest: The authors declare no conflict of interest.

\section{References}

1. Swatloski, R.P.; Spear, S.K.; Holbrey, J.D.; Rogers, R.D. Dissolution of Cellose with Ionic Liquids. J. Am. Chem. Soc. 2002, 124, 4974-4975. [CrossRef] [PubMed]

2. Pinkert, A.; Marsh, K.N.; Pang, S.; Staiger, M.P. Ionic liquids and their interaction with cellulose. Chem. Rev. 2009, 109, 6712-6728. [CrossRef] [PubMed]

3. Wang, H.; Gurau, G.; Rogers, R.D. Ionic liquid processing of cellulose. Chem. Soc. Rev. 2012, 41, $1519-1537$. [CrossRef]

4. Gupta, K.M.; Jiang, J. Cellulose dissolution and regeneration in ionic liquids: A computational perspective. Chem. Eng. Sci. 2015, 121, 180-189. [CrossRef]

5. Yuan, X.; Cheng, G. From cellulose fibrils to single chains: Understanding cellulose dissolution in ionic liquids. Phys. Chem. Chem. Phys. 2015, 17, 31592-31607. [CrossRef] [PubMed]

6. Remsing, R.C.; Swatloski, R.P.; Rogers, R.D.; Moyna, G. Mechanism of cellulose dissolution in the ionic liquid 1-n-butyl-3-methylimidazolium chloride: ${ }^{13} \mathrm{C}$ and ${ }^{35 / 37} \mathrm{Cl} \mathrm{NMR}$ relaxation study on model systems. Chem. Commun. 2006, 1271, 1271-1273. [CrossRef] [PubMed]

7. Youngs, T.G.A.; Holbrey, J.D.; Mullan, C.L.; Norman, S.E.; Lagunas, M.C.; D'Agostino, C.; Mantle, M.D.; Gladden, L.F.; Bowron, D.T.; Hardacre, C. Neutron diffraction, NMR and molecular dynamics study of glucose dissolved in the ionic liquid 1-ethyl-3-methylimidazolium acetate. Chem. Sci. 2011, 2, 1594-1605. [CrossRef]

8. Rabideau, B.D.; Agarwal, A.; Ismail, A.E. The role of the cation in the solvation of cellulose by imidazolium-based ionic liquids. J. Phys. Chem. B 2014, 118, 1621-1629. [CrossRef] [PubMed]

9. Endo, T.; Hosomi, S.; Fujii, S.; Ninomiya, K.; Takahashi, K. Anion Bridging-Induced Structural Transformation of Cellulose Dissolved in Ionic Liquid. J. Phys. Chem. Lett. 2016, 7, 5156-5161. [CrossRef] [PubMed]

10. Cheng, G.; Zhang, X.; Simmons, B.; Singh, S. Theory, practice and prospects of X-ray and neutron scattering for lignocellulosic biomass characterization: Towards understanding biomass pretreatment. Energy Environ. Sci. 2015, 8, 436-455. [CrossRef]

11. Nishiyama, Y. Structure and properties of the cellulose microfibril. J. Wood Sci. 2009, 55, 241-249. [CrossRef]

12. Martínez-Sanz, M.; Gidley, M.J.; Gilbert, E.P. Application of X-ray and neutron small angle scattering techniques to study the hierarchical structure of plant cell walls: A review. Carbohydr. Polym. 2015, 125, 120-134. [CrossRef] [PubMed]

13. Doniach, S. Changes in biomolecular conformation seen by small angle X-ray scattering. Chem. Rev. 2001, 101, 1763-1778. [CrossRef] [PubMed]

14. Le, K.A.; Rudaz, C.; Budtova, T. Phase diagram, solubility limit and hydrodynamic properties of cellulose in binary solvents with ionic liquid. Carbohydr. Polym. 2014, 105, 237-243. [CrossRef] [PubMed]

15. Rein, D.M.; Khalfin, R.; Szekely, N.; Cohen, Y. True molecular solutions of natural cellulose in the binary ionic liquid-containing solvent mixtures. Carbohydr. Polym. 2014, 112, 125-133. [CrossRef] [PubMed]

16. Hammouda, B. A new Guinier-Porod model. J. Appl. Crystallogr. 2010, 43, 716-719. [CrossRef]

17. Elazzouzi-Hafraoui, S.; Nishiyama, Y.; Putaux, J.L.; Heux, L.; Dubreuil, F.; Rochas, C. The shape and size distribution of crystalline nanoparticles prepared by acid hydrolysis of native cellulose. Biomacromolecules 2008, 9, 57-65. [CrossRef] [PubMed]

18. Leppänen, K.; Andersson, S.; Torkkeli, M.; Knaapila, M.; Kotelnikova, N.; Serimaa, R. Structure of cellulose and microcrystalline cellulose from various wood species, cotton and flax studied by X-ray scattering. Cellulose 2009, 16, 999-1015. [CrossRef]

19. Isogai, A. Wood nanocelluloses: Fundamentals and applications as new bio-based nanomaterials. J. Wood Sci. 2013, 59, 449-459. [CrossRef] 
20. Rabideau, B.D.; Agarwal, A.; Ismail, A.E. Observed Mechanism for the Breakup of Small Bundles of Cellulose I $\alpha$ and I $\beta$ in Ionic Liquids from Molecular Dynamics Simulations. J. Phys. Chem. B 2013, 117, 3469-3479. [CrossRef] [PubMed]

21. Cho, H.M.; Gross, A.S.; Chu, J.W. Dissecting force interactions in cellulose deconstruction reveals the required solvent versatility for overcoming biomass recalcitrance. J. Am. Chem. Soc. 2011, 133, 14033-14041. [CrossRef] [PubMed]

22. Liu, H.; Sale, K.L.; Holmes, B.M.; Simmons, B.A.; Singh, S. Understanding the interactions of cellulose with ionic liquids: A molecular dynamics study. J. Phys. Chem. B 2010, 114, 4293-4301. [CrossRef] [PubMed]

23. Li, Y.; Liu, X.; Zhang, S.; Yao, Y.; Yao, X.; Xu, J.; Lu, X. Dissolving process of a cellulose bunch in ionic liquids: A molecular dynamics study. Phys. Chem. Chem. Phys. 2015, 17, 17894-17905. [CrossRef] [PubMed]

24. Ando, H.; Konishi, T. Structure analysis of regenerated cellulose hydrogels by small-angle and ultra-small-angle X-ray scattering. Phys. Rev. E 2000, 62, 727-733. [CrossRef]

25. Ishii, D.; Tatsumi, D.; Matsumoto, T.; Murata, K.; Hayashi, H.; Yoshitani, H. Investigation of the structure of cellulose in $\mathrm{LiCl} / \mathrm{DMAc}$ solution and its gelation behavior by small-angle X-ray scattering measurements. Macromol. Biosci. 2006, 6, 293-300. [CrossRef] [PubMed]

26. Isik, M.; Sardon, H.; Mecerreyes, D. Ionic liquids and cellulose: Dissolution, chemical modification and preparation of new cellulosic materials. Int. J. Mol. Sci. 2014, 15, 11922-11940. [CrossRef] [PubMed]

27. Zhu, S.; Wu, Y.; Chen, Q.; Yu, Z.; Wang, C.; Jin, S.; Ding, Y.; Wu, G. Dissolution of cellulose with ionic liquids and its application: A mini-review. Green Chem. 2006, 8, 325-327. [CrossRef]

28. Takada, A.; Kadokawa, J.-I. Fabrication and Characterization of Polysaccharide Ion Gels with Ionic Liquids and Their Further Conversion into Value-Added Sustainable Materials. Biomolecules 2015, 5, $244-262$. [CrossRef] [PubMed]

29. Kunchornsup, W.; Sirivat, A. Effects of crosslinking ratio and aging time on properties of physical and chemical cellulose gels via 1-butyl-3-methylimidazolium chloride solvent. J. Sol-Gel Sci. Technol. 2010, 56, 19-26. [CrossRef]

30. Debye, P.; Bueche, A.M. Scattering by an inhomogeneous solid. J. Appl. Phys. 1949, 20, 518-525. [CrossRef]

31. Ornstein, L.S.; Zernike, F. Accidental deviations of density and opalescence at the critical point of a single substance. Proc. Acad. Sci. Amst. 1914, 17, 793-806.

Sample Availability: Samples of the compounds are commercially available from the company mentioned in Section 3 Materials and Methods.

(C) 2017 by the authors; licensee MDPI, Basel, Switzerland. This article is an open access article distributed under the terms and conditions of the Creative Commons Attribution (CC BY) license (http:/ / creativecommons.org/licenses/by/4.0/). 